\title{
PENERAPAN TEKNOLOGI EKSTRAKSI FASA CAIR-GAS PADA PENGEMBANGAN PRODUK BERBASIS JERUK KALAMANSI
}

\section{APPLICATION OF LIQUID-GAS PHASE EXTRACTION TECHNOLOGY ON DEVELOPMENT OF KALAMANSI-ORANGE- BASED PRODUCTS}

\author{
Oleh: \\ Evi Maryanti ${ }^{1)}$, Dyah Fitriani ${ }^{1)}$, Nori Wirahmi ${ }^{2)}$ \\ ${ }^{1)}$ Jurusan Kimia FMIPA Universitas Bengkulu \\ ${ }^{2)}$ Program Studi D3 Farmasi FMIPA Universitas Bengkulu \\ Email: evi.maryanti@unib.ac.id
}

\begin{abstract}
Community Service Activity (CSA) of the application of science and technology entitled "Application of Liquid-Gas Phase Extraction Technology on Development of KalamansiOrange-Based Products" has been completed. This activity aims to implement gas-liquid extraction technology, namely steam distillation in extracting essential oils from residues of Kalamansi orange syrup processing, providing knowledge and ways to process Kalamansi orange essential oil into products which have economic value in addition to syrup. It was carried out with the target audience, namely Bhakti Nusa Production Unit in SMKS 16 Bengkulu. It is done to help the production unit to develop Kalamansi-based products by utilizing residues produced by syrup which is rich in essential oils. The products produced on the CSA of the application of science and technology include aromatherapy candles, air freshener gels, anti-mosquito lotions and Bay Tat cakes of Kalamansi jam. The product produced is more widely informed through the socialization activity that received a response and enthusiasm from the audience. Products of CSA of the application of science and technology are expected to be a superior product from the Bhakti Nusa Production Unit of SMKS 16 Pharmacy as well as to be a top-quality product of the pride of Bengkulu City with high economic value.
\end{abstract}

Keywords: Extraction, Liqiud-Gas, Kalamansi, Essential oil

\section{PENDAHULUAN}

Jeruk Kalamansi adalah jenis buah jeruk yang berbau harum, memiliki rasa asam ketika sudah masak, dan pahit ketika masih mentah. Jeruk ini sejak tahun 2012 telah menjadi salah satu komoditi unggulan yang banyak dibudidayakan di Provinsi Bengkulu (Bappeda, 2012). Olahan jeruk Kalamansi yang saat ini banyak diminati dan menduduki penjualan tertinggi dibandingkan makanan khas lainnya di sentra penjualan kerajinan dan makanan khas Kota Bengkulu adalah sirup Kalamansi. Akibatnya permintaan pasokan sirup berbahan baku Kalamansi di Kota Bengkulu cukup tinggi, bahkan komoditas ini telah merambah dunia internasional seperti Hongkong, Beijing dan Australia (Sudarto WS dalam Antara Bengkulu, 2012). 
Saat ini, sudah ada \pm sepuluh industri pembuatan sirup Kalamansi di Provinsi Bengkulu baik yang berskala industri rumah tangga, kelompok maupun instansi. Salah satu unit usaha yang memproduksi sirup Kalamansi di Kota Bengkulu adalah Unit Produksi Bhakti Nusa.

Unit Produksi Bhakti Nusa (UPBN) merupakan salah satu upaya yang dilakukan oleh SMKS 16 Farmasi Bengkulu dalam mendukung program dari Direktorat Pembinaan Sekolah Menengah Kejuruan (SMK) tahun 2007 untuk menyediakan fasilitas yang dapat digunakan sebagai tempat praktik pendidikan dan latihan yang berorientasi pada dunia kerja. Secara umum, unit produksi merupakan suatu program kegiatan dalam bidang pendidikan yang dilakukan di dalam sekolah dan bersifat bisnis serta dilakukan oleh warga sekolah (kepala sekolah, ketua jurusan/program, guru dan peserta didik) dengan memberdayakan sumber daya sekolah yang dimiliki serta dikelola secara profesional untuk memberikan pelayanan prima kepada masyarakat. Unit produksi yang ada di SMKS 16 Farmasi Bengkulu sudah berdiri sejak tahun 2015. Awalnya, unit produksi ini hanya memproduksi produk berupa masker bengkoang dan bedak beras.

Saat ini, UPBN telah memproduksi produk olahan jeruk Kalamansi. Produk olahan jeruk Kalamansi yang sedang dikembangkan pada UPBN saat ini adalah sirup jeruk Kalamansi dan minyak angin aromaterapi dalam bentuk roll on. Unit produksi telah mampu mengolah $100 \mathrm{~kg}$ jeruk Kalamansi dan menghasilkan 80 liter sirup Kalamansi setiap minggunya. Cukup besarnya jumlah jeruk Kalamansi yang diolah menjadi sirup juga menghasilkan limbah kulit jeruk yang cukup banyak. Hal ini cukup menjadi perhatian pengelola UPBN untuk memanfaatkan limbah kulit jeruk menjadi produk yang berguna. Langkah yang telah dilakukan adalah mengekstraksi minyak atsiri dari kulit jeruk Kalamansi dan digunakan sebagai bahan aktif minyak angin aromaterapi. Namun karena jumlah minyak atsiri yang dihasilkan masih sangat sedikit, produksi minyak angin aromaterapi yang dihasilkan belum optimal. Selain itu, pada proses pengolahan sirup Kalamansi, juga dihasilkan residu (ampas) sirup dalam jumlah cukup besar yaitu \pm 7,5 liter setiap produksi. Saat ini, ampas sirup yang dihasilkan oleh UPBN hanya dibuang atau disimpan dilemari pendingin dan belum dimanfaatkan. Padahal residu (ampas) sirup ini kaya akan serat dan minyak atsiri yang apabila diolah dapat menghasilkan minyak atsiri dalam jumlah yang cukup besar.

Untuk meningkatkan dan mengembangkan produk olahan dari jeruk Kalamansi, maka tim pengusul ingin memberikan ilmu dan hasil dari penerapan teknologi dalam mengekstrak jeruk Kalamansi menjadi minyak atsiri. Pada tahun 2016, tim pengusul telah berhasil menerapkan teknologi ekstraksi fasa cair-gas atau dikenal dengan destilasi uap dalam mengekstrak minyak atsiri jeruk Kalamansi, dan telah membuat beberapa produk olahan minyak atsiri yang berupa minyak angin aromaterapi dalam bentuk roll on dan juga sabun cair aromaterapi (Maryanti dkk, 2017). Berbekal dari hasil penerapan teknologi ekstraksi jeruk Kalamansi, maka tim pengusul ingin berbagi ilmu kepada UPBN dalam mengoptimalkan ekstraksi minyak atsiri jeruk Kalamansi dan juga mengembangkan produk olahan berbasis jeruk Kalamansi dan minyak atsiri. Beberapa produk olahan jeruk Kalamansi yang akan dikembangkan antara lain pembuatan gel pengharum ruangan, lilin aromaterapi, lotion anti nyamuk, cake dan cookies Kalamansi. Berbagai produk yang akan dihasilkan nanti dapat digunakan baik untuk pemakaian sendiri anggota Unit Produksi, atau dapat dijual kepada masyarakat langsung dan stakesholders lainnya. Hal ini tentu saja akan memberikan dampak bagi peningkatan omset dan kesejahteraan seluruh anggota Unit Produksi Bhakti Nusa Bengkulu khususnya dan masyarakat kota Bengkulu pada umumnya. 


\section{METODE PENGABDIAN}

Kegiatan PPM berbasis Ipteks dilakukan di lokasi khalayak sasaran yaitu unit produksi SMKS 16 farmasi Bahakti Nusa Bengkulu yang beralamat di Jl. Indragiri Gang Tiga Serangkai, Padang Harapan Kota Bengkulu. Kegiatan PPM dilakukan selama 5 (lima) bulan dimulai pada Mei hingga September 2018. Untuk mencapai tujuan kegiatan pengabdian pada masyarakat yang diusulkan ini digunakan metode sebagai berikut:

1. Penyampaian informasi, diskusi dan tanya jawab

2. Pelatihan teknik ekstraksi minyak atsiri pada mitra

Perangkat yang diperlukan pada metode ekstraksi detilasi uap secara langsung ini terdiri dari 1 buah ketel yang terbuat dari plat stainless steel dengan ketebalan tertentu tergantung pada skala industri. Ketel yang digunakan pada kegiatan pengabdian IbM ini dirancang dari stainless steel dengan kapasitas $50 \mathrm{Kg}$. Selain itu juga digunakan kondensor sebagai labu pendingin untuk mengembunkan uap minyak atsiri yang dihasilkan pada proses penyulingan. Kondensor juga dibuat dari stainless dengan pipa spiral dan turbular di dalamnya. Tetesan minyak atsiri bercampur uap air akan dipisahkan di dalam alat separator yang terbuat dari bahan gelas. Minyak atsiri murni akan ditampung dalam botol berwarna gelap.

3. Pelatihan Pembuatan Pengharum Ruangan

Pembuatan pengharum ruangan dilakukan mengacu kepada hasil penelitian dari Arum Nur Fitrah (2013) yang berjudul "Formulasi Gel Pengharum Ruangan Menggunakan Karagenan dan Glukomanan Dengan Pengharum Minyak Jeruk Purut dan Kenanga". Pengharum ruangan dibuat menggunakan formulasi yang menghasilkan gel pengharum ruangan dengan ketahanan wangi terbaik yaitu dengan perbandingan kappa karagenan dan glukomanan yaitu $6: 4$, natrium benzoat $0,1 \%$, propilenglikol $10 \%$, minyak atsiri $3 \%$ dan akuades hingga 100\%. Semua bahan padat (kappa karagenan, glukomanan, dan natrium benzoat) ditimbang di atas satu alumunium foil kemudian diaduk rata. Bahan cair (akuades dan propilen glikol) ditimbang dengan wadah gelas piala terpisah. Setelah semua bahan ditimbang, akuades dipanaskan hingga suhu $75^{\circ} \mathrm{C}$ kemudian campuran bahan padat dituangkan sedikit demi sedikit sambil diaduk agar tidak terbentuk gumpalan-gumpalan kecil. Setelah hidrokoloid terbentuk, campuran didiamkan hingga suhu mencapai $65^{\circ} \mathrm{C}$, propilen glikol dan minyak atsiri dimasukkan ke dalam hidrokolid kemudian diaduk kembali dan dibiarkan pada suhu ruang hingga membentuk gel.

4. Pelatihan Pembuatan Lilin Aromaterapi

Lilin aromaterapi dibuat mengikuti formulasi hasil penelitian Prabandari dkk, 2017. Berikut ini adalah langkah-langkah pembuatan lilin aromaterapi. Penelitian lilin aromaterapi dengan menggunakan metode peleburan terhadap bahan padat. Penggunaan paraffin padat dilelehkan terlebih dahulu diatas cawan porselain yang diletakkan di atas kompor spiritus. Selanjutnya menambahkan white oil $(7,5 \%)$ ke dalam paraffin padat yang telah meleleh, pencampuran tersebut dilakukan sambil diaduk terus menerus, agar tidak memadat, lalu ditambahkan dengan minyak atsiri jeruk Kalamansi (12,5\%) sesuai perbandingan pada formula. Setelah ditambahkan minyak atsiri, campuran lilin cair dimasukkan ke dalam cetakan lilin yang sebelumnya telah dipasang dengan sumbu.

5. Pelatihan dan Pembuatan Lotion antinyamuk 
Lotion anti nyamuk dibuat menggunakan formula lotion dari penelitian yang dilakukan oleh Sari dkk, 2015. Bahan baku pembuatan lotion antinyamuk ini terdiri dari minyak atsiri jeruk Kalmansi $(0,5 \%)$, gliserin $(2 \%)$, asam stearat $(3 \%)$, metil paraben $(0,1 \%)$, trietanolamin $(0,75 \%)$, dan aquadest ad $100 \mathrm{ml}$. Dipanaskan lumpang terlebih dahulu menggunakan air panas. Gliserin dan metil paraben dilarutkan secara terpisah dalam aquades panas. Dimasukkan asam stearat dalam cawan porselin dan dileburkan di atas penangas air (M1). Kemudian dimasukkan M1, gliserin, metil paraben, trietanolamin kedalam lumpang panas dan gerus hingga terbentuk massa lotion. Ditambahkan minyak atsiri kedalam lumpang. Tambahkan sedikit demi sedikit aquadest kedalam lumpang gerus sampai homogen. Selanjutnya dimasukkan ke dalam wadah lotion yang telah di kalibrasi. Ditambahkan sisa aquadest ke dalam wadah lotion sampai $100 \mathrm{~mL}$.

6. Pelatihan dan Pembuatan Kue Bay Tat Selai Kalamansi

Kue Bay Tat selai Kalamansi dibuat dari campuran tepung terigu, gula pasir, santan, telur dan mentega yang diaduk menggunakan tangan. Campuran homogen dibentuk persegi dengan ukuran 20x20 cm, kemudian diisi dengan selai Kalamansi, dioven pada suhu $200{ }^{\circ} \mathrm{C}$ selama 30 menit.

\section{HASIL DAN PEMBAHASAN}

Kegiatan pengabdian pada masyarakat penerapan ipteks yang telah dilakukan terdiri dari beberapa tahap yaitu:

1. Pendampingan pembuatan dan penggunaan ekstraktor minyak atsiri

Pendampingan pembuatan alat ekstraktor dimulai dengan penjelasan skema bagianbagian alat dan fungsinya masing-masing. Kemudian dilanjutkan dengan pendampingan pembuatan alat di bengkel/workshop dengan diskusi dan tutorial kepada teknisi hingga alat ekstraktor selesai dan siap digunakan. Alat ekstraktor yang telah dirancang dan dibuat terlihat pada Gambar 1. Pendampingan juga dilakukan hingga pemasangan alat dan uji coba penggunaan ekstraktor di unit produksi SMKS 16 Farmasi. Beberapa anggota unit produksi yang terdiri dari penanggung jawab, instruktur, guru dan siswa dilibatkan dalam pendampingan ini (Gambar 2).

Setelah alat siap digunakan kemudian langsung dilakukan ekstraksi minyak atsiri menggunakan limbah kulit jeruk dan residu (ampas) sirup Kalamansi hasil unit produksi yang selama ini tidak dimanfaatkan. Dari hasil uji coba didapatkan residu minyak atsiri yang hampir sama dengan yang didapatkan tim pelaksana pada alat ekstraktor yang lain. Hal ini menunjukkan konsistensi dan cara kerja alat yang sudah optimal. Selain faktor alat, residu minyak atsiri yang didapat juga tergantung pada jenis jeruk Kalamansi dan kandungan air yang terdapat didalamnya. Hal ini ditunjukkan oleh berbedanya volume minyak yang didapat dari jeruk yang dibeli pada tempat yang berbeda. Limbah jeruk Kalamansi yang digunakan untuk ekstraksi minyak atsiri dan jeruk Kalamansi yang akan diambil sari buahnya terlihat pada Gambar 3 .

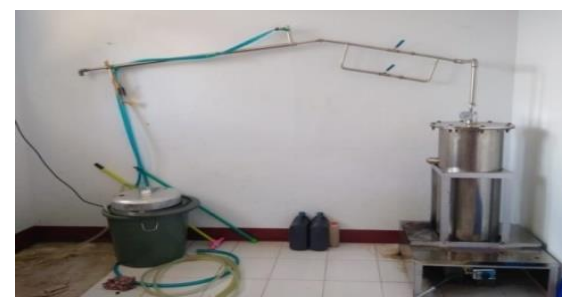

Gambar 1. Alat ekstraktor minyak atsiri Jeruk Kalamansi 


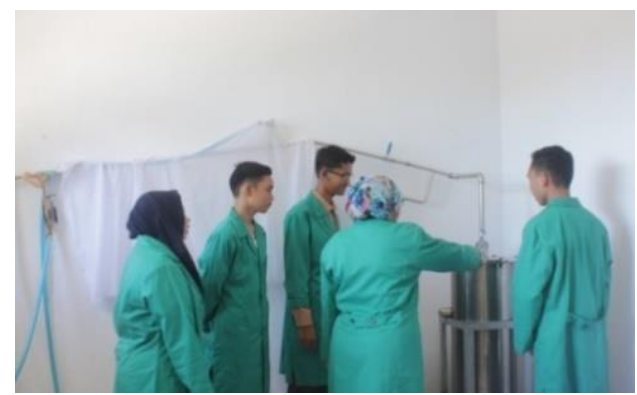

Gambar 2. Pendampingan prinsip kerja dan cara menggunakan alat ekstrakotr kepada sasaran
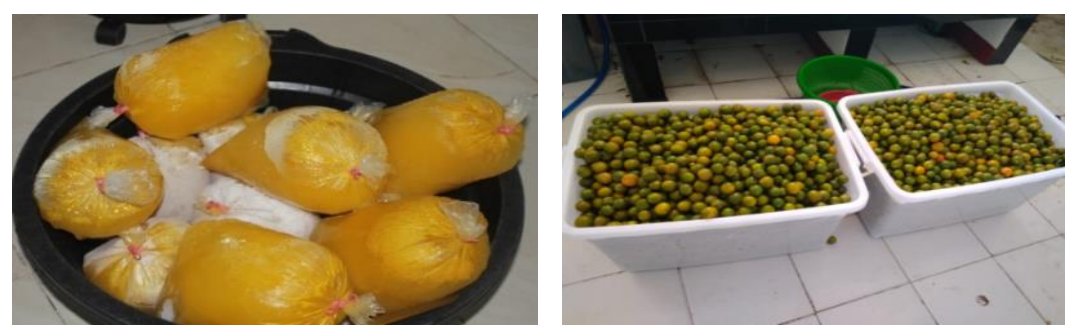

Gambar 3. Residu sirup Kalamansi dan Jeruk Kalamansi yang digunakan untuk ekstraksi minyak atsiri

Ekstraktor yang digunakan untuk menghasilkan minyak atsiri Jeruk Kalamansi menggunakan metode ekstraksi fasa cair-gas (destilasi uap) secara langsung (direct steam distillation). Pemisahan secara distilasi pada prinsipnya adalah metode pemisahan yang didasarkan pada perbedaan titik didih antara komponen-komponen yang akan dipisahkan, secara teoritis bila perbedaan titik didih antar komponen makin besar maka pemisahan dengan cara distilasi akan berlangsung makin baik yaitu hasil yang diperoleh makin murni (Kurniawan, 2014). Untuk proses ekstraksi minyak atsiri jeruk Kalamansi ini menggunakan residu sirup ditambah air dengan rasio perbandingan 1:1 dan suhu pemanasan sebesar $70^{\circ}$ selama 1 jam. Penambahan air berguna untuk mempermudah menguapkan minyak atisiri yang terperangkap dalam residu sirup dan memiliki titik didih yang sangat tinggi. Untuk menurunkan suhu pemanasan, alat yang digunakan harus tertutup rapat agar tidak ada uap yang keluar sehingga tekanan didalam ekstraktor menjadi besar. Uap minyak atsiri akan dibawa bersamaan dengan uap air dan diembunkan melalui kondensor. Agar kondensor bekerja lebih maksimal, maka pada bak penampungan air ditambahkan es batu/dry es. Hasil yang diperoleh dari destilasi berupa cairan yang terdiri dari air dan minyak atsiri, dimana minyak atsiri berada diatas dan air berada di bawah (Gambar 10). Hal ini disebabkan oleh perbedaan massa jenis minyak atsiri dan air (Wonorahardjo, 2013).
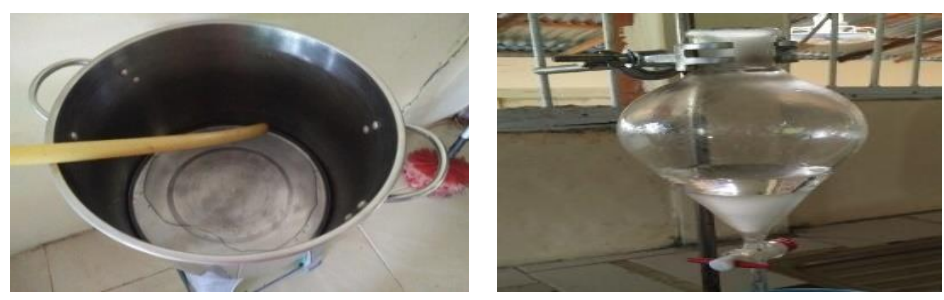

Gambar 4. Campuran minyak atsiri dan air hasil ekstraksi 
2. Pelatihan Pembuatan Gel Pengharum Ruangan, Lilin Aromaterapi dan Lotion Anti nyamuk.

Pelatihan pembuatan produk berbasis minyak atsiri dilakukan di tempat sasaran yaitu di Unit Produksi SMKS 16 Farmasi Bengkulu. Pelatihan melibatkan beberapa orang pengelola unit produksi yaitu Bidang Research \& Development serta Bidang produksi dan beberapa siswa yang dilibatkan pada unit produksi. Kegiatan dilakukan dengan memberikan pelatihan cara membuat produk berbasis minyak atisiri jeruk Kalamansi yaitu gel pengharum ruangan, lilin aromaterapi dan lotion antinyamuk. Kemudian dilanjutkan dengan diskusi dan tanya jawab mengenai formula serta masalah yang dihadapi. Kegiatan pelatihan dilanjutkan dengan evaluasi kegiatan sampai mitra telah mampu membuat produk dengan hasil yang baik.

3. Pelatihan dan Pembuatan Kue Bay Tat Selai Kalamansi

Pembuatan kue bay tat selai Kalamansi dilakukan berdasarkan pertimbangan bahwa kue bay tat merupakan kue khas daerah Bengkulu. Dimana selama ini kue bay tat menggunakan selai sebagai toping yang terbuat dari nanas atau kelapa muda. Untuk itu, pada kegiatan PPM berbasis Ipteks ini, tim pelaksana mencoba membuat variasi berbeda dari kue khas ini yaitu mengganti selai menggunakan selai dari jeruk Kalamansi. Berikut dokumentasi proses pembuatan kue bay tat selai Kalamansi yang dimulai dengan membuat adonan dari tepung terigu, telur, santan dan mentega, kemudian dibentuk persegi ukuran 20x20 cm, diisi dengan selai Kalamansi dan dioven pada suhu $200{ }^{0} \mathrm{C}$ selama 30 menit (Gambar 5).
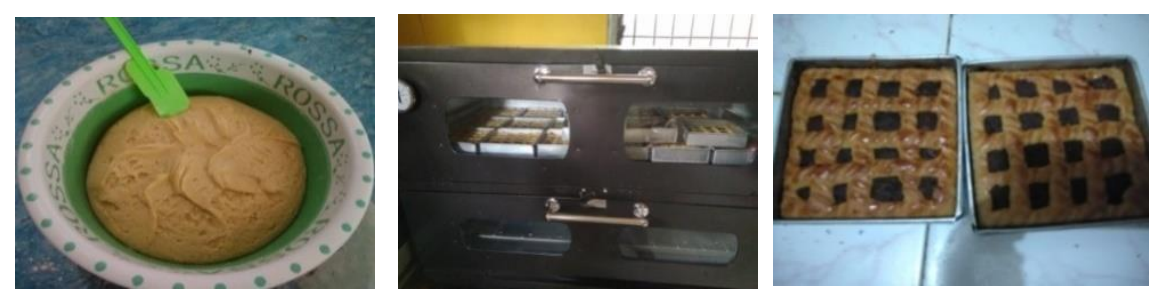

Gambar 5. Tahapan pembuatan kue Bay Tat selai Kalamansi

4. Sosialisasi Produk Hasil Kegiatan Pengabdian kepada Masyarakat terhadap khalayak sasaran (guru, tenaga laboran dan pengurus unit produksi selingkungan SMKS 16 Farmasi Bengkulu)

Kegiatan sosialisasi dilakukan bertujuan untuk menyebarkan informasi mengenai hasil kegiatan Pengabdian kepada Masyarakat yang telah tim pelaksana lakukan di SMKS 16 Farmasi Bengkulu. Kegiatan sosialisasi dilakukan setelah semua proses kegiatan pelatihan dan pembuatan produk selesai dilakukan (Gambar 6). Audiens yang menjadi sasaran pada kegiatan sosialisasi ini terdiri dari perwakilan siswa kelas X, XI dan XII dikarenakan jika dilakukan pada semua siswa akan menjadi kurang efektif karena keterbatasan tempat. Para perwakilan siswa terlihat sangat antusias dalam mengikuti kegiatan sosialisasi ini, hal ini diltunjukkan dengan banyaknya pertanyaan yang diajukan mengenai minyak atsiri dan berbagai produk yang dihasilkan serta prosedur produksi massal (Gambar 7). Selain siswa, juga dilibatkan para dewan guru dan tenaga laboran/instruktur laboratorium. Para dewan guru dan instruktur laboratorium akan menjadi penyambung informasi kepada siswa dan khalayak sasaran yang lebih luas untuk menyebarkan informasi hasil sosialisasi, seperti masyarakat umum.

Kegiatan sosialisasi dimulai dengan penjelasan mengenai prinsip dan metode ekstraksi minyak atsiri dari residu ampas sirup Kalamansi, manfaat minyak atsiri dari 
sector kesehatan dan nilai ekonomi serta berbagai produk berbasis minyak atsiri Kalamansi. Setelah penjelasan dilakukan, dilanjutkan dengan sesi tanya jawab dan diakhiri dengan pameran produk hasil kegiatan Pengabdian Masyarakat yang telah dilakukan oleh tim pelaksana di unit produksi SMKS 16 Farmasi Bhakti Nusa serta foto bersama (Gambar 8). Realisasi hasil pelaksanaan kegiatan pengabdian, termasuk foto-foto kegiatan, data-data hasil yang diperoleh selama pengabdian, hambatan-hambatan yang dihadapi selama pelaksanaan kegiatan pengabdian (Gambar 6).
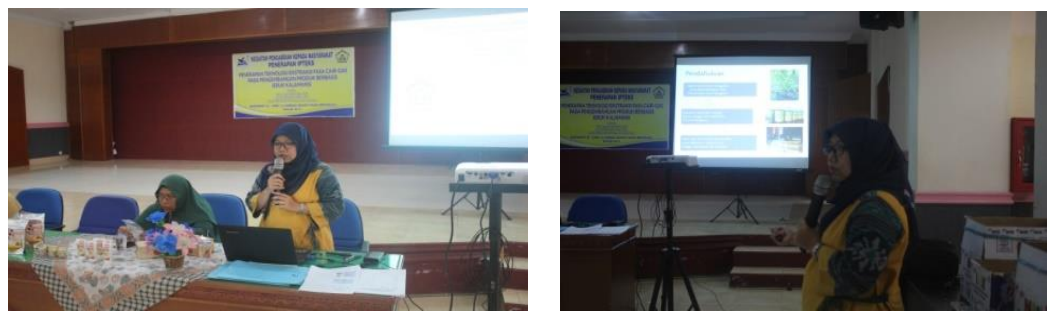

Gambar 6. Pemaparan prinsip dan metode ekstraksi serta manfaat dan produk berbasis minyak atsiri Kalamansi
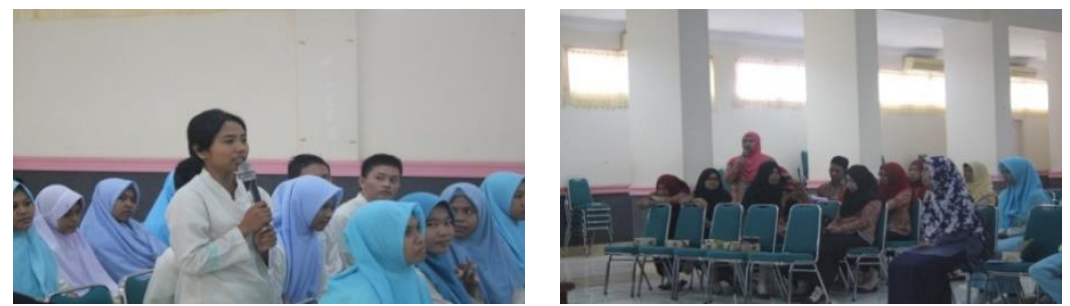

Gambar 7. Sesi tanya jawab audiens pada kegiatan sosialisasi
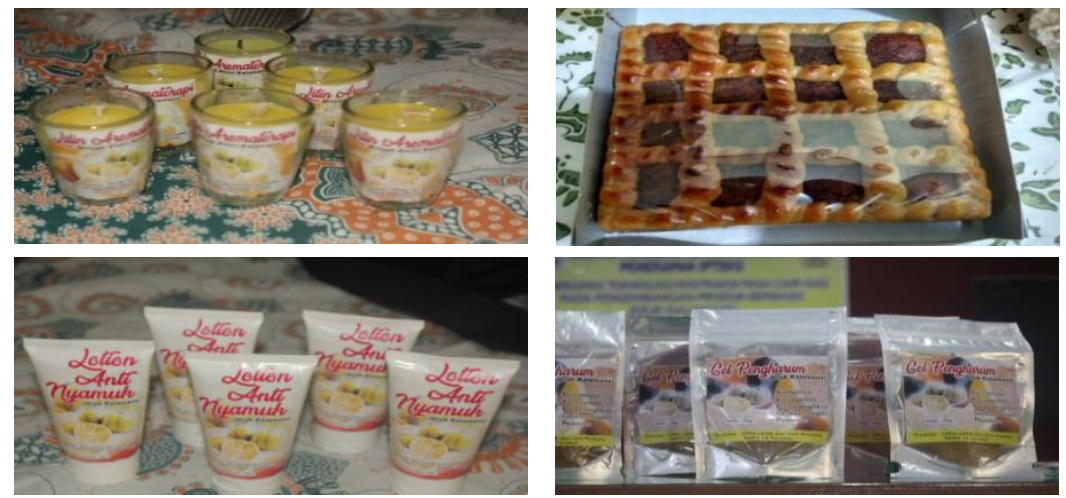

Gambar 8. Produk hasil PPM berbasis Ipteks (Lotion Antinyamuk, Gel

Pengharum, Lilin Aromaterapi dan Kue Bay Tat selai Kalamansi)

\section{KESIMPULAN DAN SARAN}

\section{Kesimpulan}

Berdasarkan hasil kegiatan Pengabdian Pada Masyarakat Penerapan Ipteks yang telah dilakukan, dapat diambil kesimpulan sebagai berikut: 
1. Telah berhasil dilakukan kegiatan berupa penyampaian informasi dan pelatihan teknik ekstraksi minyak atsiri dari limbah residu sirup Kalamansi di Unit Produksi SMKS 16 Farmasi Bengkulu.

2. Alat ekstraktor yang diterapkan telah mampu menghasilkan minyak atsiri dengan rendemen sebesar 2\% berupa minyak berwarna bening dan berbau khas jeruk Kalamansi

3. Telah berhasil dilakukan formulasi dan pembuatan produk berbasis minyak atsiri jeruk Kalamansi yaitu berupa gel pengharum ruangan, lilin aromaterapi dan lotion antinyamuk.

4. Telah dilakukan pelatihan cara membuat produk berupa gel pengharum ruangan, lilin aromaterapi, lotion antinyamuk dan kue Tat selai Kalamansi dengan hasil sesuai yang diharapkan.

5. Telah dilakukan kegiatan sosialisasi hasil PPM berbasis IPTEKS kepada siswa, guru, tenaga instruktur laboratorium dan pengelola unit produksi SMKS16 Farmasi Bengkulu dengan lancar dan audiens terlihat sangat antusias dan tertarik terhadap produk yang dihasilkan.

Dari hasil kegiatan yang telah dilaksanakan, masih terdapat beberapa kendala yaitu terbatasnya bungkus kemasan jadi dipasaran untuk produk yag dihasilkan di kota Bengkulu. Selain itu sulitnya mencari cetakan dan wadah kemasan produk di Kota Bengkulu. Tetapi kegiatan PPM Penerapan IPTEKS yang dilaksanakan telah memberikan manfaat bagi sivitas akademika SMKS16 Farmasi kota Bengkulu dan tim pelaksana dari Universitas Bengkulu khususnya serta masyarakat Kota Bengkulu pada umumnya. Disesuaikan dengan tujuan pengabdian.

\section{Saran}

Perlu dilakukan pembimbingan untuk pengemasan dan pemasaran hasil produksi kegiatan PPM.

\section{DAFTAR PUSTAKA}

Bappeda Propinsi Bengkulu, 2012, Jeruk Kalamansi dari Propinsi Bengkulu, Diakses pada tanggal 29 Maret 2016.

Fitrah, A.N, 2013, Formulasi Gel Pengharum Ruangan Menggunakan Karagenan dan Glukomanan Dengan Pewangi Minyak Jeruk Purut dan Kenanga, Skripsi. Fakultas Teknologi Pertanian, Institut Pertanian Bogor.

Kurniawan, R, 2014, Ekstraksi Minyak Atsiri Kulit Jeruk (Citrus Sinensis) dengan Metode Vakum Microwave-Assisted Hydrodistillation, Semarang: Fakultas Teknik.

Maryanti, E, Fitriani, D, Sani, F, 2017, Diversifikasi Residu Produk Olahan Home Industry Sirup Kalamansi di Kabupaten Bengkulu Tengah, Jurnal Dharma Rafflesia Tahun XV, Nomor 1 Juni 2017.

Prabandari, S, Febriyanti, R, 2017, Formulasi Dan Aktivitas Kombinasi Minyak Jeruk Dan Minyak Sereh Pada Sediaan Lilin Aromaterapi, Jurnal Para Pemikir Vol 6, No. 1.

Sari, A, Putri, N.A, 2015, Studi Formulasi Sediaan Lotion Anti Nyamuk dari Minyak Atsiri Daun Legundi (Vitex trifolia Linn), Proceding Seminar Nasional \& Workshop "Perkembangan Terkini Sains Farmasi dan Klinik 5", Padang.

Sudarto WS dalam Antara Bengkulu, 2012, Sirup Kalamansi Bengkulu Telah Merambah Dunia Internasional, Diposting pada Rabu 11 Jul 2012, 06.44

Wonorahardjo, S, 2013, Metode-Metode Pemisahan Kimia, Jakarta: Akademia Permata. 